\title{
Realities for change in child health care: existing patterns and future possibilities*
}

\author{
MARGARET STACEY
}

\section{Summary and conclusions}

In assessing some of the existing patterns and future possibilities in child health care it was found that the continuing large social class differences in morbidity and mortality may be attributed to continued poverty, both of income and therefore of diet, and also to environmental deprivation. The absence of safe places for children to play, for example, is related to the high accident rates experienced by children. Doctors admit to awareness of these social and environmental causes of unnecessary morbidity and mortality among children but have failed to address the causes directly. While the causes are outside the immediate professional provenance of doctors, it is argued that, aware as they are of this aetiology, they have a moral and professional responsibility to act collectively as a pressure group urging improvements on the relevant authorities (as they have done in the case of smoking and clean air, for example).

\section{Introduction}

In assessing where we are in child health care at the present time, and where we might be able to go, two themes are pursued: the background of child ill health and handicap and the relation between the paid and the unpaid workers. A third and important theme of the relation of the paid workers to each other in providing child health care has for the moment to be set aside. Underlying these themes are two others of importance. The first is the thin line between health and welfare, both in the aetiology of disease and in the treatment of illness and suffering. The second theme is the nature and meaning of professionalism and bears on the relation of the paid workers to each other and of all of them to the unpaid worker, the parents, and the volunteers.

\section{Background to childhood morbidity and mortality}

There are three essentials with regard to the background to child health: (1) the poverty of income and environment; (2) the close connection of health and welfare; and (3) the professional responsibility to $(a)$ encourage social and economic improvements and $(b)$ act as a pressure group.

The Court Committee ${ }^{1}$ was unhappy about our national position in the international league table of child health. They recognised the continued connection between morbidity and

*A shortened version of the introductory plenary paper given to the British Postgraduate Medical Federation's Symposium on Child Care in the Community on 22 November 1979.

Department of, Sociology, University of Warwick, Coventry CV4 7AL MARGARET STACEY, BSC(BCON), professor mortality in childhood and economic and social factors. Data from the 1971 census were not available then, but there were data about perinatal mortality by social class for 1950 and 1973, which showed that although perinatal rates had fallen since 1949 for all social classes, differences among the classes remained and had, if anything, widened.

Barbara Preston ${ }^{2}$ in analysing the data provided by the Registrar General in his Decennial Supplement for 1970-2 found that the measures of infant mortality rate, standardised mortality ratio for children aged 1 to 15 years, and the expectation of life at age 15 all show a deterioration for boys down the social scale and from each class to the next (fig 1). She points out that while

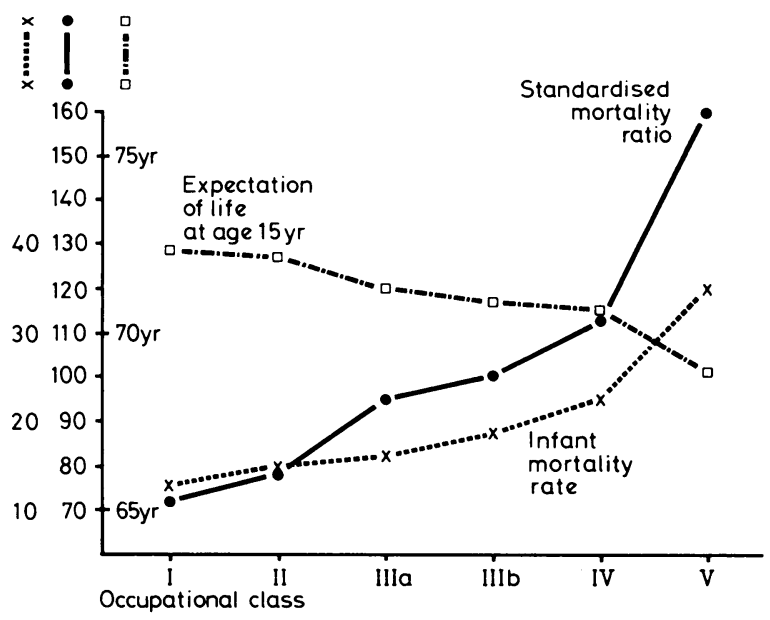

FIG 1-Infant mortality and standardised mortality rates for boys aged 1-15 and expectation of life at age 15 in different occupational classes. ${ }^{2}$

the biggest difference is between social classes IV and V, "there is a big difference between each social class, even social classes I and II ... so it is not just a question of the unsatisfactory life styles of 'problem families'" (my italics). The biggest single class differences are from child-pedestrian accidents, associated, she suggests, with the absence of safe play spaces among the less well off (fig 2).

Peter Townsend's recently published major study ${ }^{3}$ bears out the inferences Preston made. Townsend's study was based on various national inquiries and a special study of 1968-9, which shows that deprivation rises as occupational class declines (fig 3 ). One-third of children aged 1-10 were said to have no safe place to play (25\% of children aged $1-4$ of professional and managerial parents compared with $44 \%$ of children in semi-skilled or unskilled parents). All the three measures of air pollution, garden, and a safe place to play rise by social class. All are highly correlated. Taken overall two-thirds of the families of manual workers had a pronounced degree of environmental deprivation.

Poverty and environmental deprivation were associated, but 
the association was to some extent masked by variations in tenure and other variables. About $8 \%$ of all children from birth to 14 years are in poverty, and something over a further threequarters are on the margins of poverty. ${ }^{3}$ Townsend defines poverty by the State's standards of the income below which State provision does not permit a family to fall.

Work by Wilkinson, ${ }^{4}$ currently being refined by Leech and Cowling in the Warwick Economics Department, suggests that these poverty data may be of considerable importance. Their work, using multivariate analysis, suggests that the component of "social class" which is responsible for variations in mortality

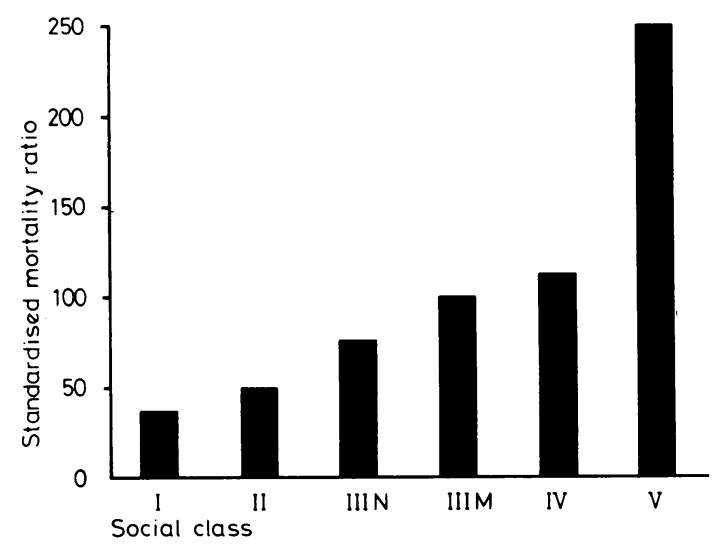

FIG 2-Standardised mortality ratio for boy pedestrians by social class. ${ }^{2}$

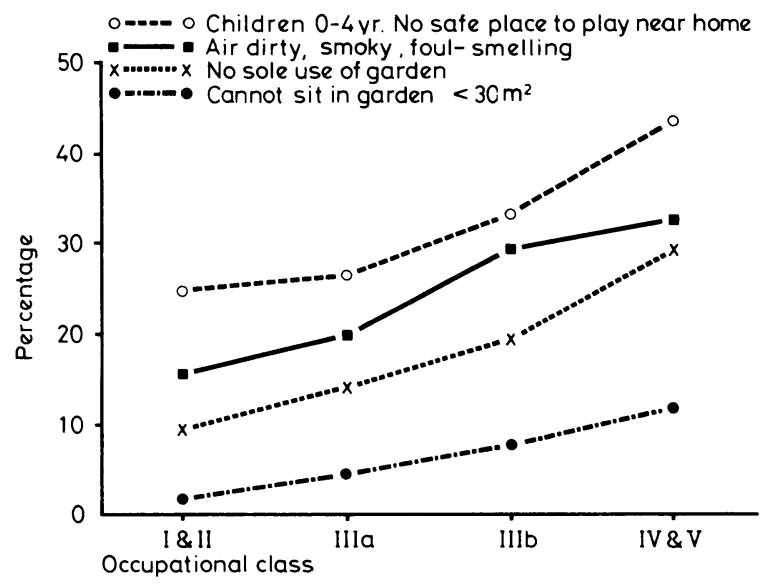

FIG 3-Percentages of environmental deprivation by occupational class. $^{3}$

is income. Within this, diet is probably the crucial variable. So social class relates to death rates through income, diet, and environment (University of Warwick Department of Economics Mimeos by $\mathrm{D}$ Leech and $\mathrm{K}$ Cowling. Health, income, and social class (November 1978) and Diet and mortality in Great Britain: a cross-sectional grouping approach using national food survey (January 1980)).

The Court Committee ${ }^{1}$ was aware of these phenomena and their implications for health, although these particular measures -that is, the Preston, ${ }^{2}$ Townsend, ${ }^{3}$ and Wilkinson ${ }^{4}$ data and the 1971 census-were not available to them at the time of their deliberations. The committee emphasised the importance of social class differences: "Social class V contains a higher proportion than other classes of those families where adverse circumstances-for instance, low income, bad housing, and poor education-combine to place children at great risk of ill health or accident."
The committee fully understood the importance of adequate income, decent environment, and housing for good health, and attributed much of the generally improved levels of health among children to the greater affluence of the second half of the twentieth century compared with the nineteenth and early twentieth centuries. So far so good.

The conclusions the committee drew from these data are disappointing. One would have expected that given the unequal chances to achieve fitness the committee might have drawn really strong attention to the problems; and that in the name of children fit for the future they would have called firmly on those in government responsible for this sad state of affairs to make amends: to improve housing; to reduce pollution; to increase safety; to look to the adequacy of welfare benefits; to examine critically their employment (or unemployment) policy. But they did not. Of course, it is outside the scope of the NHS itself to do these things. But where health-care professionals are clearly appraised, as the Court Committee was, of the social causes of disease, it seems proper that those in the NHS who recognise the consequences of bad social conditions should act as a strong pressure group to try to get these remedied. Sadly, all the report could find to say was, "Adverse social conditions will doubtless be with us for many years to come." So they will if strong attempts are not made to change them. Professional responsibility in this matter is increased now that we are faced with reductions or removal of the welfare benefits available to the severely disadvantaged that go some way to ameliorate their lot: free school meals and milk are two such threatened services.

Rather than drawing attention to collective responsibility in this way the Court Committee reacted as so many other of our advisers have reacted recently, including Dr David Owen when he was Secretary of State for Health and Social Services. They have emphasised the responsibility of the individual to help maintain good health. ${ }^{1}$

There is, I am sure, a great deal more that we could all learn about how to avoid ill health. Those of us who are better off, however, have the most choice about our life styles. Parents living under motorway junctions are aware of the polluted air their children breathe; parents whose toddlers have no place to play but the street know that this is dangerous. There is little point educating mothers to follow a correct diet if the relevant fresh foods and vegetables are not to be found in the corner shops on their housing estates and the buses to bigger shopping centres are expensive or non-existent.

A division has come about in our minds and in our institutional arrangements between health and welfare, so that we no longer think as clearly as we might on these issues. Once illness has occurred it is right and proper that health care professionals should do all in their power to override these unfortunate consequences as I made plain elsewhere. ${ }^{5}$ But we do have to get our priorities right. Eliminating the social causes of diseases in childhood is as important as eliminating the individual causes.

There is a great fashion nowadays for health education, echoed in the Court Report, and money is available for this purpose even when cuts are being made. This is well and good, but it can only be undertaken successfully within an understanding of the social and economic circumstances of the families to be educated. As the Court Report recognised, the evidence of the incidence of differential disease among social classes "underline(s) the importance of preventive medicine." 1 It went on to regret that it is these very people who are most at risk who use the services least.

\section{Relation between the paid and the unpaid workers in child health}

There are three points to be made here: (1) the responsibility placed on and accepted by parents, especially mothers; and (2) the devaluing of the parents, because-(3) professionalism drives a wedge between the parents and the child-care professional. 
With the increased emphasis on personal responsibility and in the individualistic philosophy of our society we tend to say, "What is the matter with these people that they do not come to use our services ?" rather than asking, "What is the matter with our services that these people do not use them ?" Brotherstone, ${ }^{6}$ who understands more than many about the differential effects of socioeconomic variables on the population, advocated "outreach" services. The Court Report recognised this in its suggestion for a child health visitor who would regularly visit homes, saying, "It is essential for contact with clinic nonattenders." 1 The report recognises also the need for flexible hours for clinics because many mothers cannot attend during normal working hours. ${ }^{1}$ Nearly one-quarter of mothers of children under 5 work at least part-time, most of them because they have to, and over half of those with children aged 5-16.

\section{Essential tasks}

There are perhaps three essential tasks in health care-health maintenance; health restoration; and amelioration of chronic conditions where the restoration of full health or full functioning is not possible.

The most important work in health maintenance is done by people who are unpaid, mostly the parents and mostly the mothers. Traditionally, the provision of an adequate income is the father's task. But often mother's help is needed or she is the sole earner: providing an adequate diet, cleaning the house, preparing the food, and generally watching to see that a child is growing up correctly, in a moral as well as a physical sense, falls particularly on the mother. She is a primary health worker: but you never hear her described in that way. At the same time her work in this area is well recognised.

\section{The mother's lot}

My colleague, Hilary Graham, ${ }^{8}$ has shown in a recent survey of mothers, which she called rather neatly "Prevention and health: every mother's business," that the great majority of mothers are keenly aware of their responsibilities for the health of their families. She points also to the burdens and anxieties the mothers feel as a consequence of all the exhortations put on them by professionals and governments. The emphasis on personal prevention that has been the keynote of recent health policy bears particularly heavily on the mother. "Since children's health is seen to depend upon and be mediated through the family, children themselves cannot be exhorted to take on responsibility for their own health nor to institute major changes in their lifestyle ... these tasks pass to their parents: it is they who oversee changes in lifestyle necessary to secure their children's health." "The new philosophy of child health (she goes on to say) "emerges as something closely akin to the traditional notion of maternal sacrifice which permeated the nineteenth and early twentieth century writings on the familyfor instance, Llewelyn Davies."

But she points to a change. The new terminology refers to "parents" or "the parent" thus portraying "an image of the modern family as a homogeneous unit in which traditional childrearing roles are blurred and the burden of childcare is equally shared by the parents." In practice, permeating the work of people such as Mia Kelmer Pringle ${ }^{10-13}$ and the Court Report, ${ }^{1}$ it is clearly the mother who is in mind: the reports thus underline the traditional breadwinner/child rearer division in a normal nuclear family.

Mothers are urged to changes in lifestyle both for themselves and for their children. The mother's commitment to regular medical surveillance for herself and her child is seen as crucial. So here enters the anxiety about the underusers expressed in the Court Report.

Graham $^{8}$ and her colleague, Lorna McKee, interviewed 200 mothers during pregnancy and in the first six months after birth. They found that, "the current concern with mothers' lack of responsibility may well be misdirected, for mothers already appear to possess that sense of responsibility that the proponents of prevention wish to engender." The researchers found in the women "a sacrificial attitude to their own life style, in which they place the health needs of their families above their own." They also found among the mothers a "sense of guilt and culpability about the potential, suspected, or actual ill-health of their child."

Finding this, Graham and McKee perceived that "patterns of behaviour which place a child's health at risk appear to result not so much from lack of responsibility, but rather from a conflict of responsibility coupled with an uncertainty about how best to meet the competing demands that the family makes upon the mother" (their italics). The responsibilities and anxieties emerged during pregnancy with women being specially worried about how their lifestyle might affect the fetus; they also experienced conflict, not knowing how to balance their fears that sexual intercourse might damage the fetus with their husbands' sexual demands. Similar conflicts and uncertainties emerged in childbirth and later in child rearing. Mothers found that their commitment to breast-feeding conflicted with their commitments to their other children, their husband, their housework, and themselves. The conflicts emerged again over the crying child. "Mothers felt unsure and confused about why the baby was crying and yet at the same time they felt they should (as mothers) know both the cause of the crying and a way to control it." 8

In the light of these data, which as Graham says are echoed in other works, ${ }^{1415}$ the "exhortations for greater maternal responsibility and self-sacrifice appear at best superfluous, and at worst likely to exacerbate women's already heightened feelings of inadequacy and guilt." Graham concludes therefore that present policy with regard to preventive health misses its target. A broader perspective on prevention is needed: a perspective which, firstly, would recognise the economic constraints that shape family life and, secondly, would consider the way the external constraints are mediated and deflected within the home, recognising the sacrificial role of the mother and questioning the division of labour within the home. ${ }^{8}$

\section{Devaluing the parents}

These findings of Graham echo earlier discussions that took place in the team doing work focusing on the effects on children of entering hospital. ${ }^{16} 17$ We observed the parents' difficulties in dealing with professionals. The parents considered that they were not taken seriously. They also thought that there was no proper way in which they could behave. As we used to put it among ourselves, you were either "a careless parent or an anxious mum." Either way it was wrong. The notion that "a mother knows best" seems somehow to have disappeared. Nowadays it is only professionals who know, and mothers experience considerable conflict and anxiety as a result.

This has emerged again in recent work that I have been doing with medical colleagues in which we have been assessing the effectiveness of certain child development centres. When a child had a defect that was not obvious to professionals at the immediate postnatal check or to clinic doctors at subsequent visits, parents sometimes had great difficulty in persuading professionals that their child did have a problem. In several cases the parents were in the end proved to be right: there was something the matter with their child. I know of three cases (two turned up in surveys and one recounted to me by a doctor) of mothers who repeatedly took their child to the general practitioner because they were sure "something was wrong." In each case the mother was dubbed "an anxious mum" and prescribed tranquillisers. In each case it finally emerged that the child had congenital deformity of the hip. Mothers were right to be anxious, and chlordiazepoxide (Librium) was not the correct prescription. 
We drew attention to this problem in our first report on one of the child development centres. The prompt and sympathetic response of the staff was to decide that "a mother is right until she has been proved wrong." How well this is working in practice only a further survey would show. The professional feeling that mothers "don't know" because they are not trained goes deep. Reports frequently indicate that patients or, in the case of children, their parents are devalued by professionals. Yet the main burden of health maintenance falls on the parents and specifically on the mothers. The rhetoric recognises this but is, as Graham $^{8}$ has argued, misdirected. Professionalism drives a wedge between the parent and the child-care professional: the practice therefore often reinforces the feelings of guilt and inadequacy suffered by the mothers.

One of the things about the Court Report ${ }^{1}$ that pleased me most was the recognition throughout of the importance of parents. Once again, the disappointment came in the recommendations at the end. Among the many proposals for modifying the structure of the health care professions to try and improve the child health service there were no recommendations at all that would give structured recognition to the importance of the parental role, no proposals for formal arrangements to ensure that parents are included in the child care team. Yet to achieve the sentiments of the report such a change has to be made. Similar contradictions emerge in the report of the Jay Committee, ${ }^{18}$ which says, at the outset, how important the family is, especially for children, yet there is really relatively little attention paid to the family in the end.

In the body of the report the committee reminds us that $80 \%$ of severely handicapped children and $40 \%$ of severely handicapped adults live in their own homes. "The contribution of families is not fully recognised by those who plan and provide residential care." The committee points out that: "The existing system has often forced parents into making desperate choices: many have cared for their children at home almost entirely unsupported, others have found the burden too great and have seen no alternative but to make a complete separation from their child and request for him to be placed in an institution."

Furthermore, in line with Graham's arguments ${ }^{8}$ any parents of a handicapped child reading Better services . . ${ }^{19}$ who thought they could not manage their handicapped child at home would be made to feel guilty, such is the emphasis on home care and parental responsibility. For my part, I have always thought such a moralistic emphasis to be misplaced. Most do look after their own children remarkably uncomplainingly.

The Jay Committee ${ }^{18}$ correctly reports encouraging signs that the major divide between institutional care and the home is being reduced. Yet the contrast between professional and domestic still lingers on. When discussing putting children into foster homes, the Jay Committee says that alternative homes should be sought where: (a) there is a good support system; (b) the substitute parents are trained (so they seem to be becoming semi-professionals: my comment); (c) a reasonably high financial allowance is made; and $(d)$ there is a positive commitment and enthusiasm on the part of the social services, local education authority, and NHS support staff.

If such a similar list were laid down for the parents and carried through the removal of the child might have been avoided in the first place. The difficulties staff have in maintaining relations with parents and with volunteers is discussed but not analysed. Full analysis and understanding of these difficulties is needed if the aims of the Jay Committee are to be realised.

\section{Conclusions}

(1) For successful comprehensive child health care, doctors must act as a pressure group against poverty and environmental deprivation. They have taken pressure-group action, for example, with regard to smoking, alcoholism, and clean air. Why not act on these other matters that so much affect child health ?
(2) The parents and especially the mothers have to be revalued.

(3) We need to think more of collective health hazards and act against them-for instance, the creation of a "contemporary public health movement." 20

\section{References}

${ }_{1}^{1}$ Department of Health and Social Security. Fit for the future: the report of the committee on child health services. Cmnd 6684. London: HMSO, 1976. (Court Report.)

2 Preston B. Further studies of inequality. Sociol Rev 1979;27:343-50.

3 Townsend P. Poverty in the United Kingdom: a survey of household resources and standards of living. London: Penguin, 1979.

4 Wilkinson RG. Socio-economic factors in mortality differentials. University of Nottingham, 1976. (M Med Sci Thesis.)

${ }^{5}$ Stacey M. New perspectives in clinical medicine: the sociologist. $f R$ Coll Physicians Lond 1979;13:123-9.

${ }^{6}$ Brotherstone J. Inequality, is it inevitable? In: Carter C, Peel J, eds. Equalities and inequalities in health. London: Academic Press, 1976. (Galton Lecture, 1975.)

${ }^{7}$ Anonymous. Survey of women working. Woman's Own 1979 Feb 17:22.

${ }^{8}$ Graham H. Prevention and health: every mother's business: a comment on child health policies in the 70s. In: Harris C, ed. Sociology of the family: new directions for Britain. Sociological Review Monograph No 28. University of Keele, 1979.

${ }^{9}$ Davies ML. Maternity: letters from working women. London: Virago, 1978.

10 Pringle MK. The needs of children. London: Hutchison, 1974.

11 Pringle MK. Setting the scene. Concern 1975;17:6-8.

12 Pringle MK. A policy for families-or for children ? Concern 1976;22:2530.

${ }^{13}$ Pringle MK, Hooper WM. Giving children a chance. Community Care 1977 Nov $9: 20-2$

14 Gavron H. The captive housewife. London: Routledge and Kegan Paul, 1966.

15 Rapaport R, Strelitz Z. Fathers, mothers and others. London: Routledge and Kegan Paul, 1977.

16 Stacey M, Dearden R, Robinson D, Pill R. Hospitals, children and their families. London: Routledge and Kegan Paul, 1970.

17 Hall D, Stacey M, eds. Beyond separation: further studies of children in hospital. London: Routledge and Kegan Paul, 1979.

18 Department of Health and Social Security, Scottish Office, Welsh Office. Report of the committee of enquiry into mental handicap nursing and care. Cmnd 7615. London: HMSO, 1979. (Jay Committee.)

19 Department of Health and Social Security, Welsh Office. Better services for the mentally handicapped. Cmnd 4683. London: HMSO, 1971.

${ }^{20}$ Dennis J, Draper P, Griffiths J, et al. Rethinking community medicine: towards a renaissance in public health. London: Unit for Study of Health Policies, Guys Hospital Medical School, 1979.

(Accepted 11 March 1980)

\section{Has there been any clinical trial of co-trimoxazole in neonatal meningitis?}

The manufacturers do not recommend using co-trimoxazole in the first few weeks of life. This is presumably for two main reasons: the well-known inability of the newborn kidney to excrete drugs as efficiently as at other ages, and the theoretical danger that cotrimoxazole could displace bilirubin from protein binding sites in jaundiced infants. Its use has, however, been reported ${ }^{\mathbf{1}}$ in five infants, most with Escherichia coli meningitis, whose ages ranged from 8 days to 1 month; all had been considered therapeutic failures after parenteral treatment with conventional antibiotics. One child, with myelomeningocele and hydrocephalus, died of other complications with sterile cerebrospinal fluid; the remaining four improved rapidly. Two further infants, ${ }^{23}$ both with myelomeningocele, who developed meningitis at about 2 weeks of age due to $E$ coli in one and Pseudomonas cepacia in the other, were successfully treated with the drug. The Swedish authors ${ }^{1}$ showed that high concentrations were achieved in serum and cerebrospinal fluid with a total daily intravenous dose (given 12 hourly) of $30-40 \mathrm{mg}$ sulphamethoxazole and $6-8 \mathrm{mg}$ trimethoprim, both per $\mathrm{kg}$, without signs of accumulation.

\footnotetext{
Sabel K-G, Brandberg $\AA$. Treatment of meningitis and septicemia in infancy with sulphamethoxazole/trimethoprim combination. Acta Paediatr Scand 1975;64:

Darby CP. Treating Pseudomonas cepacia meningitis
methoxazole. Amer $\mathcal{A}$ Dis Child $1976 ; 130: 1365-6$.

Morzaria RN, Walton IG, Pickering D. Neonatal meningitis treated with trimethoprim and sulphamethoxazole. Br Med $f 1969 ; \mathrm{ii}: 511-2$.
} 